The heritagization of a Mediterranean vernacular mountain landscape. Concepts, problems and processes.

\author{
Altaba Tena, Pablo ${ }^{1} \&$ García-Esparza, Juan A. ${ }^{2}$ \\ ${ }^{1}$ Doctoral student at School of Architecture, Universitat Politècnica de València. \\ Valencia.Spain.pabalte@arc.upv.es \\ ${ }^{2}$ Senior Lecturer at Department of Mechanical Engineering and Construction, \\ Universitat Jaume I. Castellón de la Plana. Spain. Corresponding author. \\ juan.garcia@emc.uji.es
}




\title{
The heritagization of a Mediterranean vernacular mountain landscape: Concepts, problems and processes.
}

\author{
The concepts of heritage and landscape have always changed or been developed \\ based on the social context of the time. For decades, attempts have been made to \\ find a pragmatic definition for a changing setting where values, evolve or \\ disappear in step with the changing ways and styles of life of each society. \\ Heritage and landscape have inherent values such as identity, culture, authenticity \\ or integrity, that is to say, landscape character. Current heritagization processes \\ that lead to an understanding of the palimpsest of landscape and heritage layers \\ need to be participatory and inclusive as their importance and sustainability \\ depend on this. This article shows how the early stages of a heritagization process \\ unfold in a small region of the western Mediterranean, Penyagolosa (Castellón). \\ The current problems of the region - depopulation, abandonment and loss of \\ culture and identity - are assessed in search of an understanding and appreciation \\ of a heritage landscape. The research uses techniques such as photo elicitation in \\ a workshops, GIS analysis and evaluates the different options to characterize the \\ landscape offered by different researchers. The analysis explains the different \\ phases of the research to establish the basis of the heritagization of this setting. \\ The study also established a parallel perspective for valorization between \\ researchers and local population - objective and subjective visions - thus \\ encouraging the interest of the social majority linked to the landscape.
}

Keywords: Vernacular Landscape; Identity; Local communities; Heritagization; Cultural landscape

\section{Introduction}

In some Mediterranean regions rural spaces are transformed from spaces for production and life to become spaces for consumption and conservation (Holmes 2012). It is possible to find an axiomatic contradiction at the heart of the technical, theoretical and scientific disciplines currently studying landscapes: the intersection of the material reality of landscape and the collective cultural image which one wishes to transmit. At the same time, a disconnect is observed between the perspective held by landscape 
specialists, most of the society living in these landscapes, and occasional visitors. The multifunctional and multidisciplinary nature of the landscape has led landscape researchers and analysts to find a study methodology that can define the disconnect between what can be seen and what is desired.

The current situation in heritage landscapes is linked to a cultural shift which has led the intrinsic values of heritage being abandoned and instead be understood as social constructs (Parkinson, Scott, and Redmond 2016). In keeping with this, the values of landscape are understood to be, by definition, mutable. New types of values appear while others are grouped together or simply disappear (De la Torre 2013). This rigid system results in an incomplete understanding of values (Fredheim and Khalaf 2016). While values are seen as mutable adaptive concepts, the concepts of integrity and authenticity also adjust to new perspectives (García-Esparza 2016). In this regard, ICOMOS (1994) highlighted the need for conceptual change and evolution to find a broader vision of the authenticity of cultural assets. Authenticity, commonly understood in opposition to thematization, is associated with the preservation of functions and meanings (Silva and Fernández 2017), viewing heritage as an experience and as social and cultural representation with which people are actively involved (Smith 2011). Equally, the fact that places may have inherent qualities without cultural significance is defended (De la Torre 2013), adding that individuals recognize values in a specific location based on their own needs or desires, and shape these based on their social, cultural or economic circumstances (Spennermann 2006). It should thus be stressed that the conservation of a place must identify and take into consideration all aspects of its cultural and natural significance, avoiding unwarranted emphasis to the detriment of others (ICOMOS 2000).

Integrity should also be included as a quantifiable factor in studies of the landscape. 
Gullino and Larcher (2013) mention the different perspectives and degrees of integrity based on the fields of knowledge from which landscape is evaluated. They support multidisciplinarity as the middle ground for the assessment of the integrity of landscapes as integrity is connected with conservation. However, the given value in itself is not a quality. Instead the fabric, object or medium is the carrier of a specific cultural or historic meaning imposed externally and based on the dominant frameworks of a specific period (Pendlebury and Gibson 2009).

In terms of cultural significance, landscape is a key element in the identity of a specific area or region. This idea refers to the concept of attachment and the traditional aspects of attachment to the place of origin and dependence (Hammitt, Kyle, and Oh 2009). Some researchers added other dimensions such as affective attachment (Kyle, Mowen, and Tarrant 2004), social ties (Kyle, Graefe, and Manning 2005) and familiarity, belonging and roots (Hammitt, Backlund, and Bixter 2006). This identification can be linked to a specific element of the landscape, the historical relationship between a local community and its surroundings. Identity is not necessarily linked to a particularly striking landscape, but can be linked to an ordinary or deteriorated landscape (Council of Europe 2000; Plottu and Plottu 2012). Thus, heritage and landscape represent the individual identity and idiosyncrasy of local communities.

Another situation to be taken into account when attempting to deconstruct a landscape is the perhaps unsuitably termed 'cultural identity'. Given that identity and culture are complementary concepts, confusion leads to them being sometimes used synonymously. Culture refers to routine practices, beliefs and meanings which are strongly established, while identity refers to feelings of belonging to a place or collective. The problem in theory stems from the provable empirical fact that the cultural limits do not always coincide with those of identity. In a social group with which all members identify there 
is not necessarily cultural homogeneity (Grimson 2010). On the one hand there are identities which are not outlined and could be the basic identities transmitted from one generation to the next, while on the other there are identities that are imposed or outlined and created by the administration (provinces, states...) (Mira 2007).

A landscape can be recognized as cultural by different collectives or communities although only some of these will recognize it as identitarian (Silva and Fernández 2017). Therefore, identity must be homogeneous in order to view the rest of values as heterogeneous because of their social perception. Therefore, the identity tends to be homogeneous but the perception of each observer makes the rest of the values heterogeneous according to their own subjectivity. One of the most important aspects of the notion of identity of the landscape is that it provides an idea of the subtle balance between aggregation and segregation. It can unite people in a feeling of attachment to their region. This can lead to interest and involvement in the conservation and development of the spatial and existential characteristics of the landscape. A multidisciplinary holistic interpretation of these processes could lead to the creation of a collective conscience in search of common objectives (Stobbelaar and Pedroli 2011) or as Watson and Waterton (2010) hold, the creation of a heritage community.

\section{Area under study}

The history of Mediterranean vernacular mountain landscape reflects successive waves of human population growth and decline, with the first traces of human activity dating back to Neolithic settlements (Gasco and Gutherz 1983). Since the Middle Ages most of the Mediterranean highlands have undergone changes. The original scattered mediaeval settlements in the highlands and their successive layers of occupation came about from necessity, which led to self-sufficiency in exploiting land resources. This 
gave rise to a less natural landscape which displayed many features of highly humanized space. The recent history of these vernacular landscapes continues to evoke imaginaries from the past by means of still practiced and experienced rituals vernacular Mediterranean landscape. Vernacular dwellings, epitomizing a mediaeval culture based on mobility and living off the land, came to be seen as a symbol of stability, independence, attachment to the land, and of a code of conduct and morality (Jackson 1990). Despite major economic and social changes, the autonomous households, the surviving spatial patterns, the buildings' arts and crafts, and the territorial histories contributing to this context persist until the present day (García-Esparza 2018).

The western Mediterranean is characterized by a process of change which has greatly affected the small communities in the mountainous Mediterranean region since the mid20th century. The case study is located at the east of the Sistema Ibérico mountain range, the area of Penyagolosa in Castellón (Spain). This variable ground ranges from 400 to 1800 metres above sea level, which conditions the climate producing four different bioclimatic layers depending on altitude and orientation. The municipalities of the territory under study around this mountain have been affected by migration to major nuclei. It has also changed from secularly rooted socioeconomic, agriculture and livestock systems to secondary and tertiary sectors, always conditioned by rural tourism.

This is why the buildings scattered over a landscape dedicated to housing (masías (farm houses), mills, almazaras (oil mills)) are either in disuse or have gone on to be used as second homes, generally conditioned by proximity to municipalities or roads. In this rocky landscape, terracing was built to increase the area of cultivatable land. Nowadays few of these terraces are still used for agriculture as these are not accessible to agricultural machinery. Most production is found on the plains, easier to access with vehicles and extensively farmed. A similar process is found in many European countries 
with socioeconomic and environmental implications such as depopulation and the decline of agrarian ecosystems, with the subsequent loss of biodiversity (Figure 1).

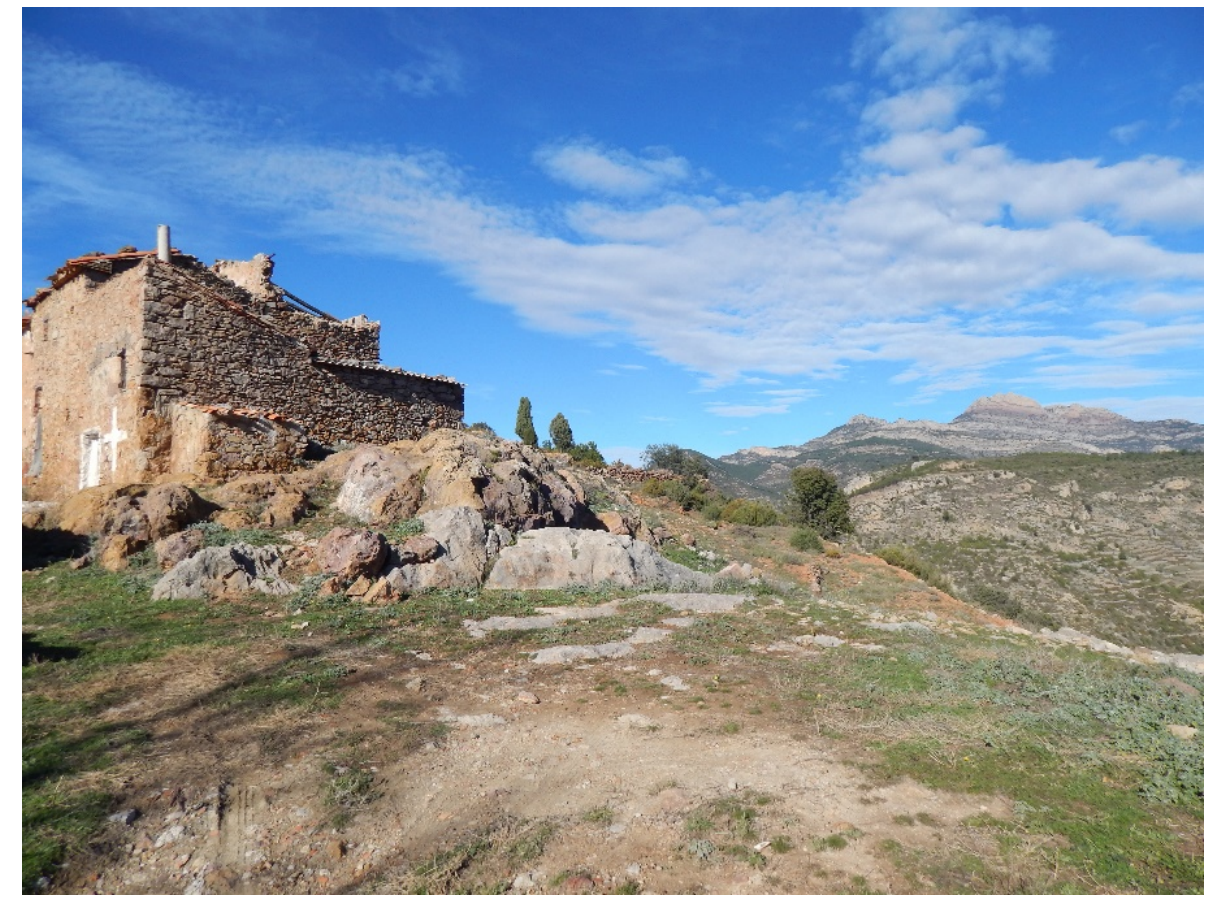

Figure 1- Example of area under study. In the foreground, a masía, a traditional farm house with a spontaneous display of a religious symbols linked to the pilgrimage values.

This landscape can be well linked to the autotopic construction of space. It escapes from the heterotopic or idealistic constructed scenarios of the past (Fairclough, 2012), and further reinforces the idea of conserving those habitats created by the ethnicities of autochthonous rural dwellers, what in turn forces new interpretations on the cultural diversity of the unplannable or informal in landscape values. These autotopias (Berger, 2015) refer to past and present spatial practices where the role of the non-expert is empathised, where ordinary residents participate in the intellectual and material construction of 'informal' places (García-Esparza 2018). Although this autotopic landscape suffers decay, abandonment and deterioration, it transmits the social truth of a modest population. Current loss of inhabitants together with the relative abandonment of this type of pseudo-indigenous rural life not only poses a relative threat to specific 
preservation criteria, but also sets interesting challenges for the economic, cultural and environmental viability of the place (Agnoletti 2014).

Research in the entanglements of this landscape took into account the positive and negative factors which could condition the perception of the material reality of the territory. During workshops we discussed about stakeholders' interpretation of these informal landscapes and we noticed how they were confronting the heterotopic and autotopic imaginaries in the search for values. For this purpose, the research team and other people linked directly to the landscape observed and catalogued the different ethnographic elements and agricultural architecture, connected with water use: masías, mills, almazaras, wheels, fountains, bridges, etc., which can still be found, albeit abandoned or no longer in use (Altaba 2018). This architecture is linked to the landscape and strategically placed to make the best possible use of environmental conditions. In addition, this network of itineraries links rivers, municipalities and the hermitage at the foot of Mount Penyagolosa which has been the destination of pilgrimages since the Middle Ages.

The anthropic landscape used drystone walls to parcel off crops. The anthropic landscape used dry stone for a combination of reasons: for modifying the permeability of mountains in order to retain water, to make land profitable, to denote the boundaries of plots, to retain livestock or to make constructions where to keep tools and agricultural implements. The presence of essential water resources was observed, combined with great biodiversity, and spontaneous displays of need and faith, highlighting the specific values of this sociocultural setting (see Figure 1). The landscape thus contained vernacular settlements in areas near water sources or rivers and creeks; even models which use the agricultural-forest landscape to build masías reflecting the fervent religiosity that still coexists with the other values of the landscape. 
Connotations of sustainable environments rely on specific aspects of places, including population numbers, the division of different local, regional or national actors, and how they assume the responsibility which results from attempts to balance the concepts of ecology, economy and socialization of spaces. Currently the conservation policies of these heritage spaces are geared towards the fossilization of the landscape through strict protection to conserve the wealth of vernacular architecture in the region (Figure 2).

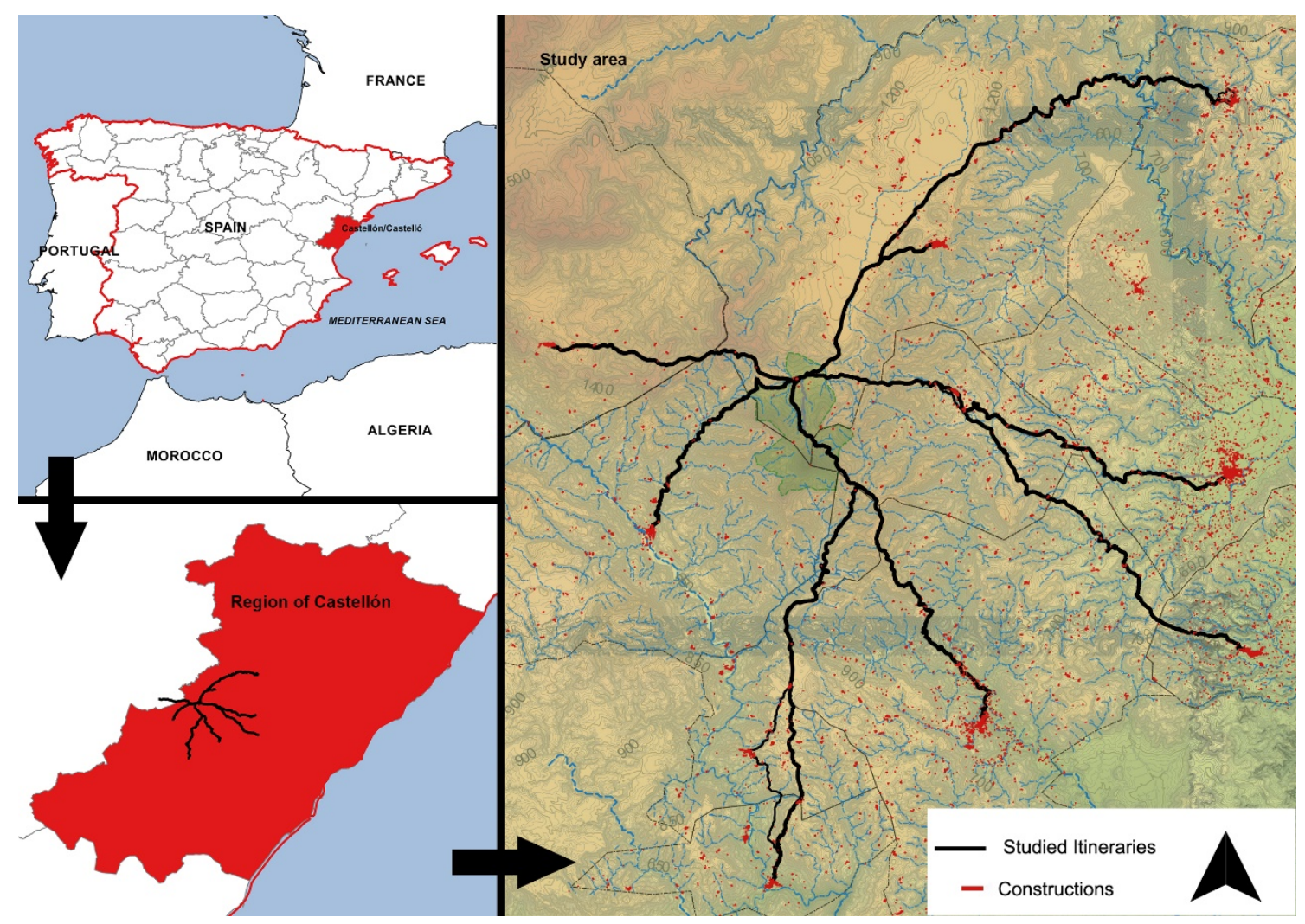

Figure 2 -The area under study is located in the province of Castellón, along the eastern Mediterranean coast of Spain.

\section{Case study methodology}

The primary aim of the research was to bring together experts and residents views of the cultural landscape. For this reason, the topics were examined in participatory meetings in order to establish joint starting points regarding basic landscape-heritage concepts. Participation in the conceptualization process was aimed at 
an equal footing, in spite of the existence of disagreements, it ensured inclusive crosscutting relationships between experts and citizens. This is achieved due to the deliberate identification and assessment of sociocultural, economic and environmental interactions which make up the landscape (Dalglish and Leslie 2016). Participation is thus not used as a shield or a mere validation method (Sánchez-Carretero and Jiménez-Esquinas 2016).

Many researchers have explored the assessment frameworks of the characteristics of landscape and heritage. Recent examples of these assessments include the proposals of English Heritage (2008), assigning four value ranges depending on typology: proof value, historic value, aesthetic value and communal value. In contrast, another framework which focused on the theory of values was implemented by Stephenson (2008) in the Cultural Values Model, which divided heritage into form, relationships and practices.

The aim of an integrated vernacular landscape process is a focus on both the tangible and intangible nature of landscapes in order to interpret them through an 'authorized' classification process (Pendlebury 2013). Other frameworks proposed an initial focus on the stories, then on importance and finally on other locations (Pocock, Collett and Baulch 2015). The process proposed by Speed et al. (2012) was also taken into consideration: comparison and analysis of the difference in the integration and assessment of natural and cultural values, observing differences when assessed separately and combining aspects of nature and culture. Finally, Harrison (2015) developed a dialogical heritage model, focused on a fluid examination of the relationship between heritage and other social, political and environmental matters. These models view the different fields as interconnected at the most basic and complex levels. 
In view of these studies, meetings and interviews were set up in order to establish how residents perceived the landscape. According to Fredheim and Khalaf (2016), value typologies are separate between professionals and residents, resulting in difficulty obtaining a complete interpretation. However, the methods used in the interviews included the Landscape Character Assessment, that is applicable to different landscapes and based on scale, intrinsic characteristics and value (Swanwick, 2002; Tudor, 2014). However, an 'authorized' classification of landscape reduces it to a monument independent from cultural values and meanings of place (Smith 2006, 2011, 2013; Pendlebury 2013). Since Butler (2016) suggested that LCA differentiates objectivity and subjectivity too much, scholars and residents came together to combine both visions: the objective vision academically set by analytical criteria and study and a subjective vision that links it to the land, moulding it at times, but providing an understanding of a rigorous analysis of all the tangible and intangible values relating to this territory.

For that purpose, in the first place, 211 elements were catalogued in the area studied, including masías, mills, fountains, wheels, bridges and churches. The 165 kilometers of itineraries were divided into 13 days that took approximately three months. In each workday, the objective was to georeference the specific location of each construction by means of a global positioning system. By means of standardized questionnaires, the construction elements linked to the itineraries under study were catalogued. The state of conservation of these elements was as follows: $28 \%$ in good condition; $47 \%$ in need of urgent intervention due to the risk of collapse; and $25 \%$ in ruins. In these field days, the team was guided by people from the municipalities that are part of the study area. Links began to be forged between the technical team and the local population.

In order to learn more about the connection between society and the heritage landscape 
of Penyagolosa and its surroundings a series of meetings were held to explain the analyses being conducted.

To evaluate the perception of this vernacular, abandoned and decaying cultural landscape, 100 residents of the eight municipalities studied were surveyed. The objective of the survey was to establish the perception of the architecture linked to the landscape, to the itineraries that connect the municipalities with Mount Penyagolosa, as well as questions about their traditions, their link with the territory and their references within the vernacular cultural landscape.

Based on previous experience and broadening the field of environmental perception and increasing the number of participants surveyed (400 people) it was decided to carry out a photo-elicitation workshop asking also for concepts that were added to the results of the first contact.

Two factors should be taken into account, the scale of what is perceived and the attachment and identification mentioned earlier. Therefore, it must be added that the choice of scale on which to interpret a certain element, a certain landscape or a certain territory is crucial in order to transmit what kingdoms we find in them (Folch and Bru 2017). These scales can be the following:

(1) The biological scale $(<1: 100)$

(2) The architectural scale (1:100 to 1000)

(3) The urban or ecological scale (1: 1000 to 10000)

(4) The microterritorial scale (1:10000 to 50000)

(5) The macro-territorial scale (1: 50,000 to 250000$)$ 
We will call this phenomenon a scale of perception (Riesco, Gómez and Álvarez 2008), in the case of photo-elicitation, to perceive the authenticity or state of conservation and a concrete impression of an element, the first two scales were used.

A photo-elicitation workshop provided images of locations representative of the values of the area in order to highlight their importance and analyses the ties people had with their surroundings. Firstly, the research shows that photo-elicitation doesn't replace studies based on conventional interviews and can be viewed as an adjunct to such methods, providing additional validity and depth, and offering new viewpoints and opportunities (Arias 2011). As photo-elicitation is a relatively time-consuming activity (for researchers and informants), it should preferably be adopted when it can provide an effective contribution to the research. Secondly, photo-elicitation stimulates the informants' ability to express their practical knowledge through the attribution and association of meanings. In these activities, the informants will not only provide information, but they will also be asked to describe their perceptions of specific phenomena and the values they attribute to them (Bignante 2010).

With these premises, it was asked about natural, historical, ethnographic, productive, religious and social values. This classification was obtained through fieldwork, consultation with experts from the Penyagolosa natural park and through the first surveys of the local population. Each of the values is defined below. The interpretations were obtained through the study of the results of the following materials (Figures 3 to 5).

(1) Natural value: this value is made up of the biotic and abiotic elements that can be found in the landscape, 
(2) Ethnographic value: this value is made up of the elements related to vernacular architecture and the elements linked to it,

(3) Historical value: this value is composed of intangible elements that are reflected in the vernacular tradition of the region,

(4) Social value: this value is made up of activities related to the territory, whether they be sporting, recreational or educational,

(5) Religious value: this value is made up of traditional representations such as pilgrimages or the buildings in which they are represented (churches, hermitages and sanctuaries) and

(6) Productive value: this value is made up of the traditional activities linked to agriculture and stockbreeding and the products derived from these activities.
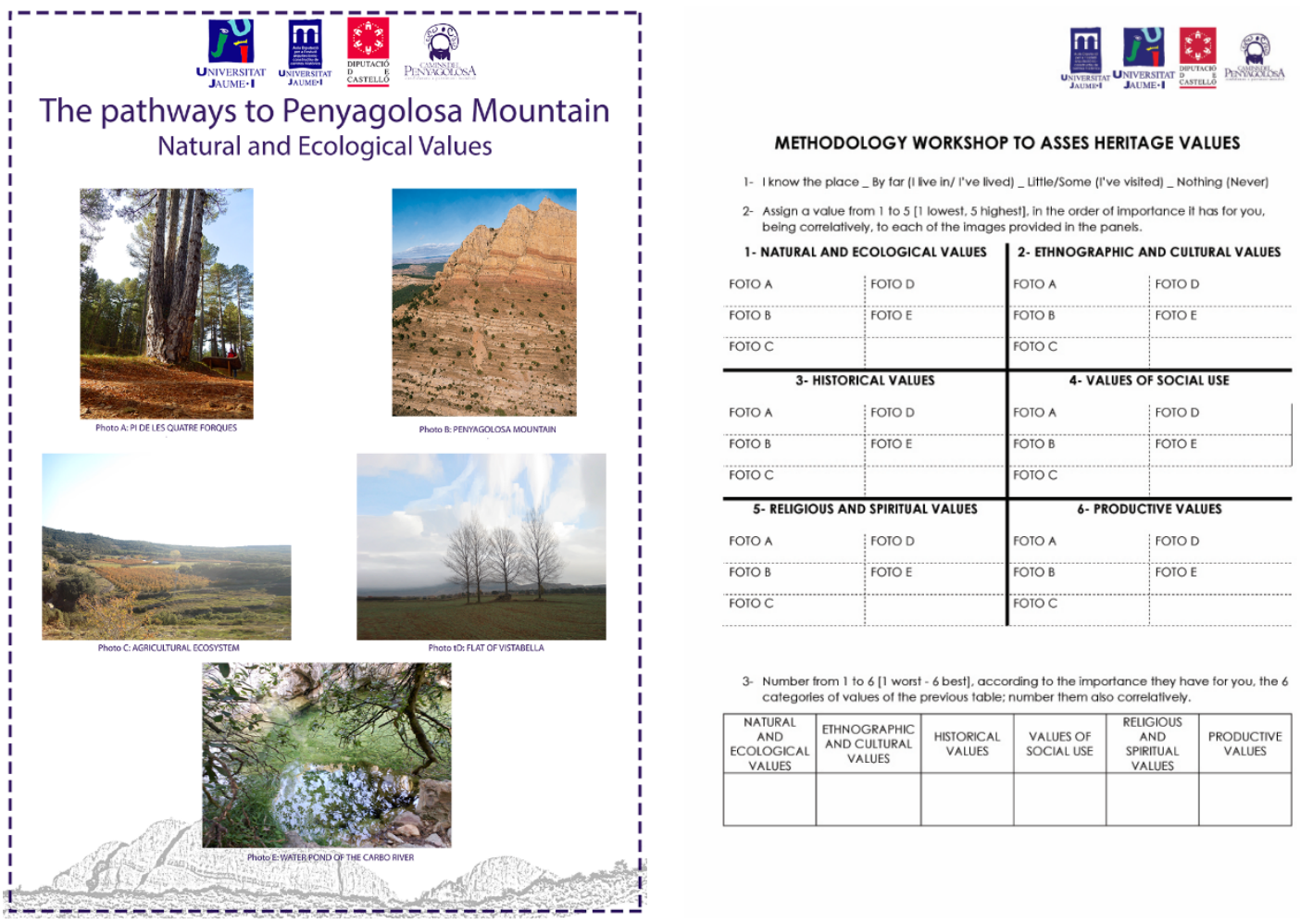

Figure 3 and 4 - Material used for the photo-elicitation workshop. Figure 3 provides 5 of the images referring to the natural value evaluated by the population. Figure 4 is the rubric used to record the results. 


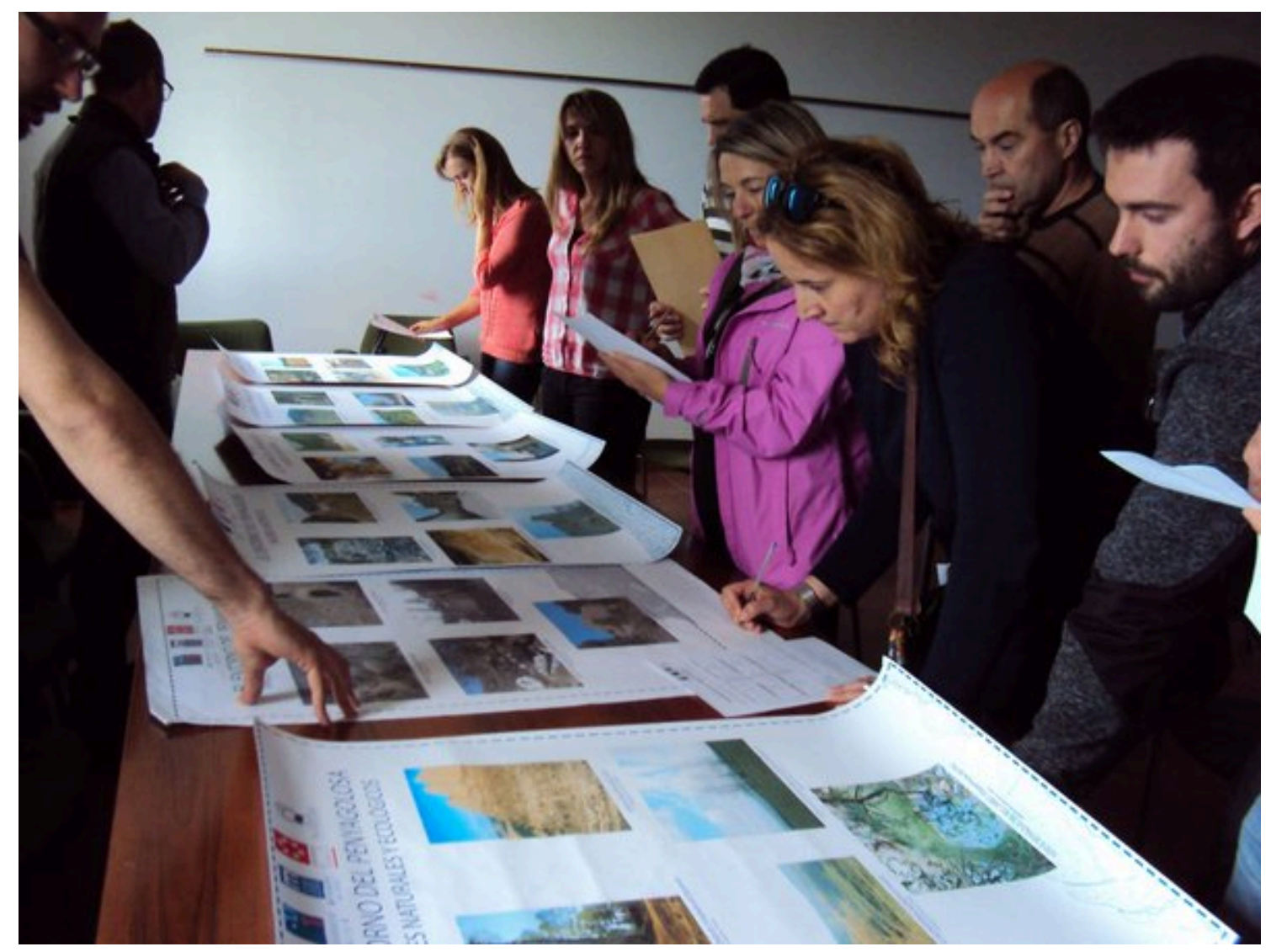

Figure 5 - Photograph of the workshop with inhabitants of the study area. The perception of the landscape values.

At the core of cultural studies is the interpretation of signs. A common criticism of cultural studies is that researchers often assume how audiences or a public define hegemonic or other ideological messages. Photo elicitation offers a means for grounding cultural studies in the mundane interpretations of culture users. Several elicitation studies focused on the meaning of local cultures. In these studies, a researcher takes photographs of a group doing its normal round of activity. Surveys among the local population inspire subjects to define how they interpret the elements represented (Harper 2002). 


\section{Findings}

\section{Perception of integrity and authenticity}

When residents were asked to describe the condition of the architecture the terms most frequently used were 'poor or unaesthetic', an option selected by $100 \%$ of interviewees in one of the municipalities. In seven of the eight municipalities 'poor or unaesthetic' was the most frequent choice. In contrast, the least common result was that describing the abandonment as 'good or aesthetic', which option only featured in three of the eight municipalities and always in less than $10 \%$ of cases. Finally, the option of 'indifferent or logical' was used in all municipalities except in one where it matched the option 'poor or unaesthetic'.

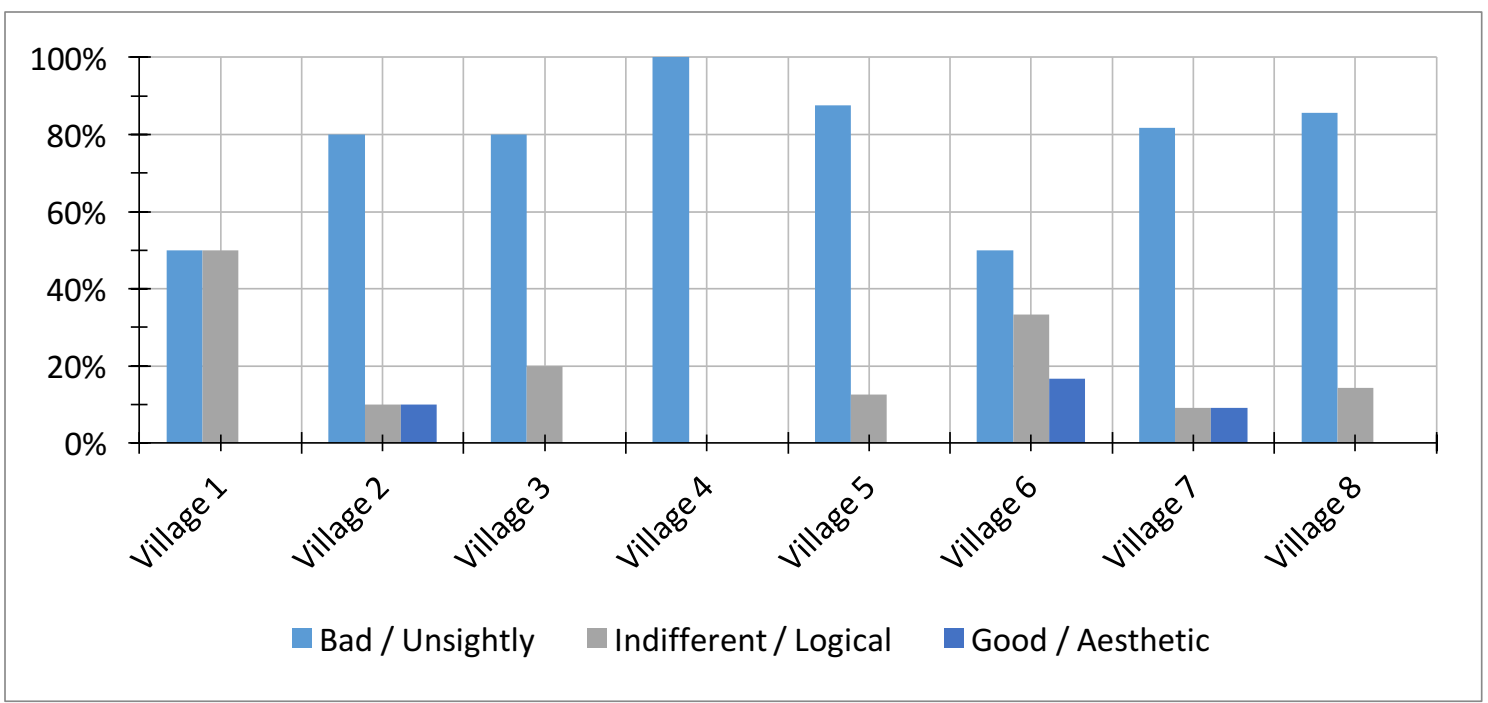

Figure 6 - Percentages of responses in the eight villages on the perceptions of the visual quality of abandoned vernacular architecture.

For the second survey, the aim was to ascertain the criteria of the locals regarding the authenticity of landscape. Responses were divided into three groups: (a) the landscape contains and conserves the original anthropic use, (b) the landscape contains the use, but due to abandonment some anthropic components are not visible and (c) the landscape has completely lost all signs of past uses (Figure 7). Although the results are practically 
the same for options (a) and (b), it is worth noting the perception on the use of landscape in municipalities 2 and 6 , with $75 \%$ and $85 \%$ of the population respectively seeing the original anthropic use in its surroundings. The fact that in all cases except one the original use of the landscape was perceived by over $40 \%$ of those surveyed is positive and a significant exercise in collective memory for the research. Secondly, for option (b), the results are around $50 \%$ of the total of the survey although it should be noted that in two of these municipalities the results are above the average, showing that these are aware of the state of emergency of local ecosystems more awareness exists in the abandoned of local ecosystems. Finally, option (c) was not selected in 5 of the 8 municipalities, and was below $10 \%$ in two municipalities, only reaching $18 \%$ in one case.

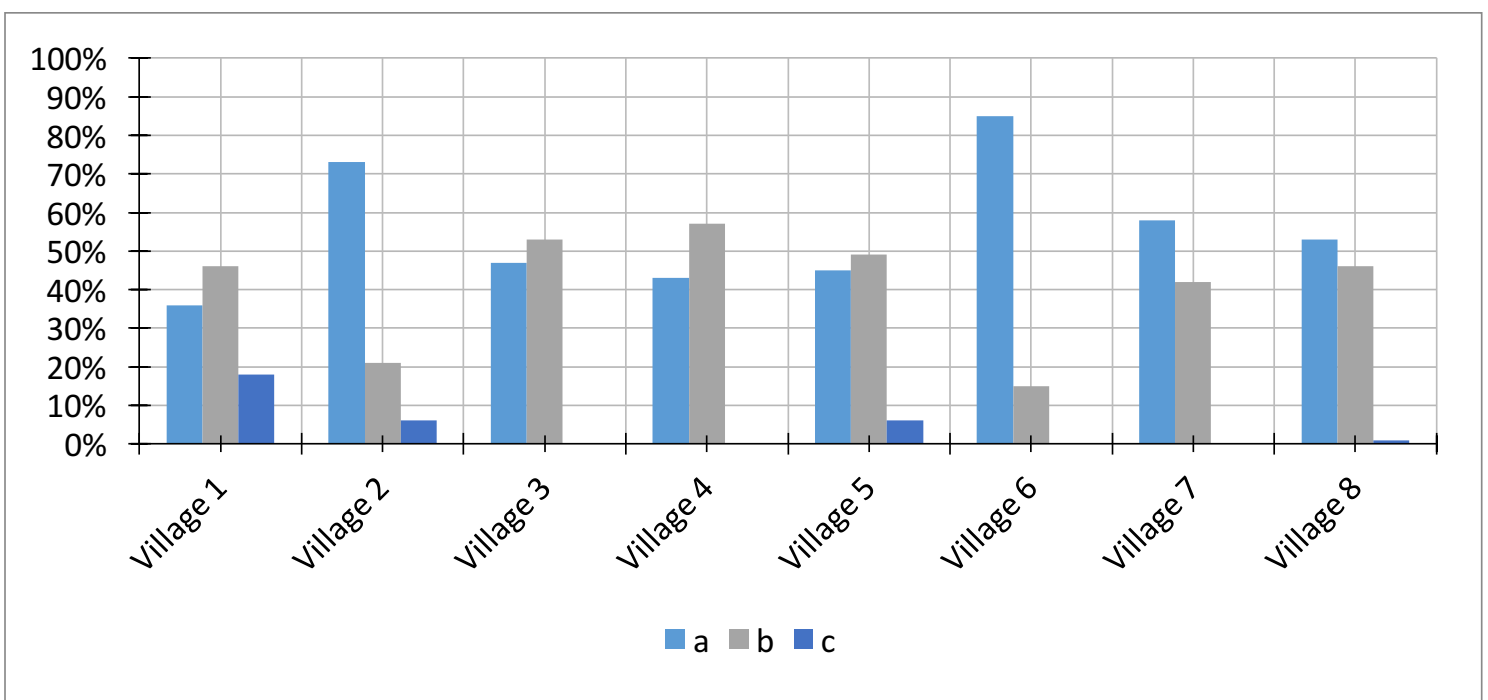

Figure 7 - Percentages of responses on the perception of authenticity of the landscape.

Comparison of the results of both surveys shows two notable inverse trends: abandonment of architectural elements is considered negative, while the visual quality of the landscape is perceived as positive.

The first element in which to assess attachment and identification was an almost derelict 
small-scale building. On it residents identify the traditional way of life, as if it could be traced back representing links of familiarity, belonging or attachment (Hammitt, Backlund, and Bixler 2006). Nonetheless they also identified the element linked to a negative view of evolution, losing historical, cultural and ethnographic values which became vestiges of a past time (Figure 8).

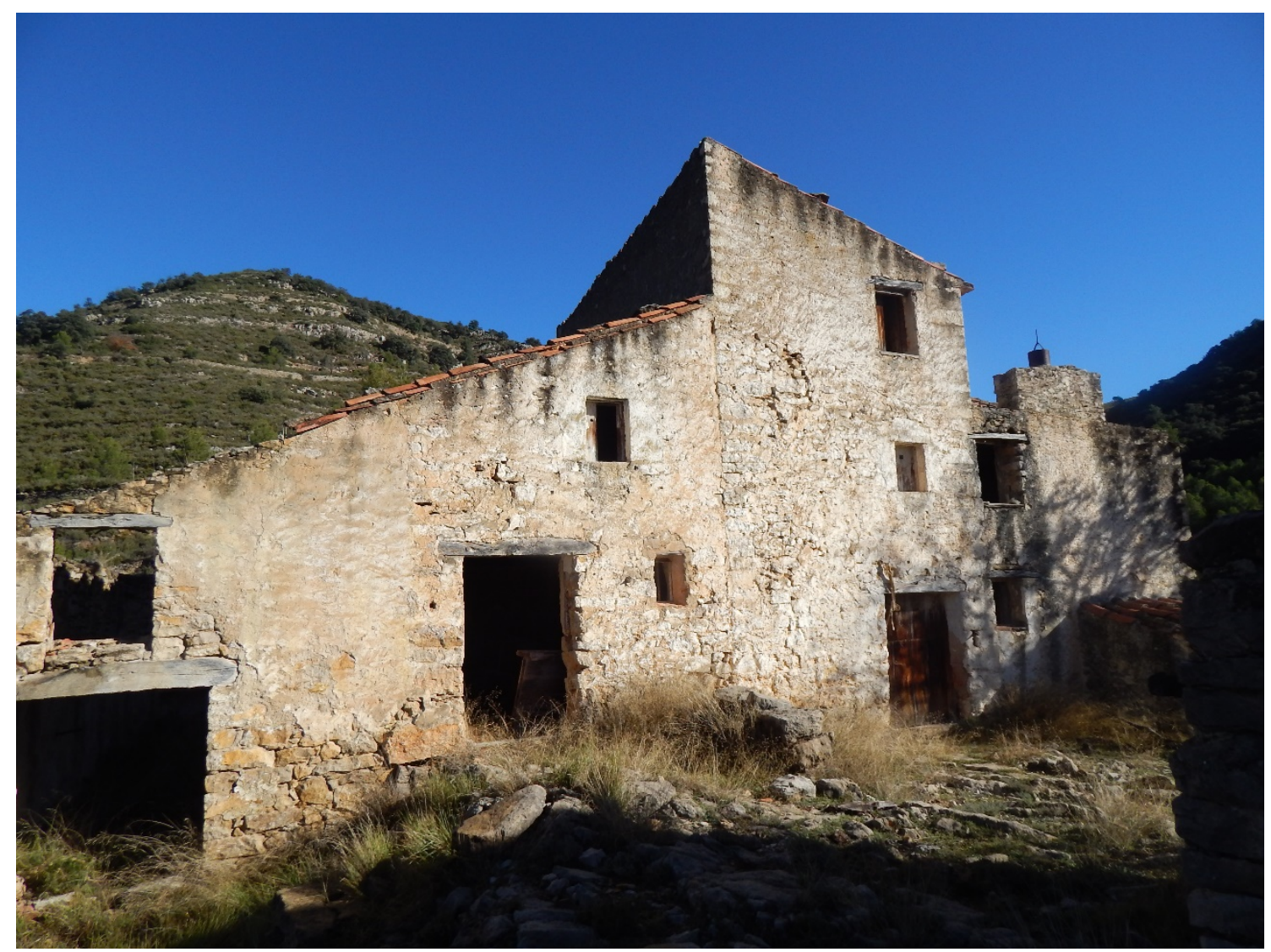

Figure 8 - First picture of the ethnographic elements at the photo-elicitation survey. As shown in Figure 3.

While buildings tend to deteriorate, landscape adapts to the climate and production circumstances imposed on it. However, the surveys showed that apart from the negative perspective of the surroundings, environmental changes are ignored while the parts of the landscape which transmit positive values are highlighted. Therefore, the social connection (Kyle, Graefe, and Manning 2005) which landscape creates with residents continues to exist, although with current uses and customs. 


\section{Perception of the values of the landscape}

Using the photo-elicitation mentioned above, together with the incorporation of landscape values (natural, religious, productive, ethnographic, historical and social), identified in the field work described in the methodology of this work and evaluated from the material in Figures 3, 4 and 5, it was proposed to catalogue the importance of the landscape and heritage values according to the value attached by local residents (see results in Figure 9).

Natural value was recognized as the most important, followed by ethnographic value. Historic value and social value obtained similar results, while production value was rated the least important. Paradoxically, the production value which configured the rural space under study came last in the surveys for most municipalities. However, there is a value which depends on the secular tradition of making pilgrimages, out of necessity and faith - rain, health and peace - to the church of Penyagolosa. The municipalities where these traditions are still present see religious value as the most important. In contrast, in villages which no longer practice the tradition of pilgrimages religion is least valued. 


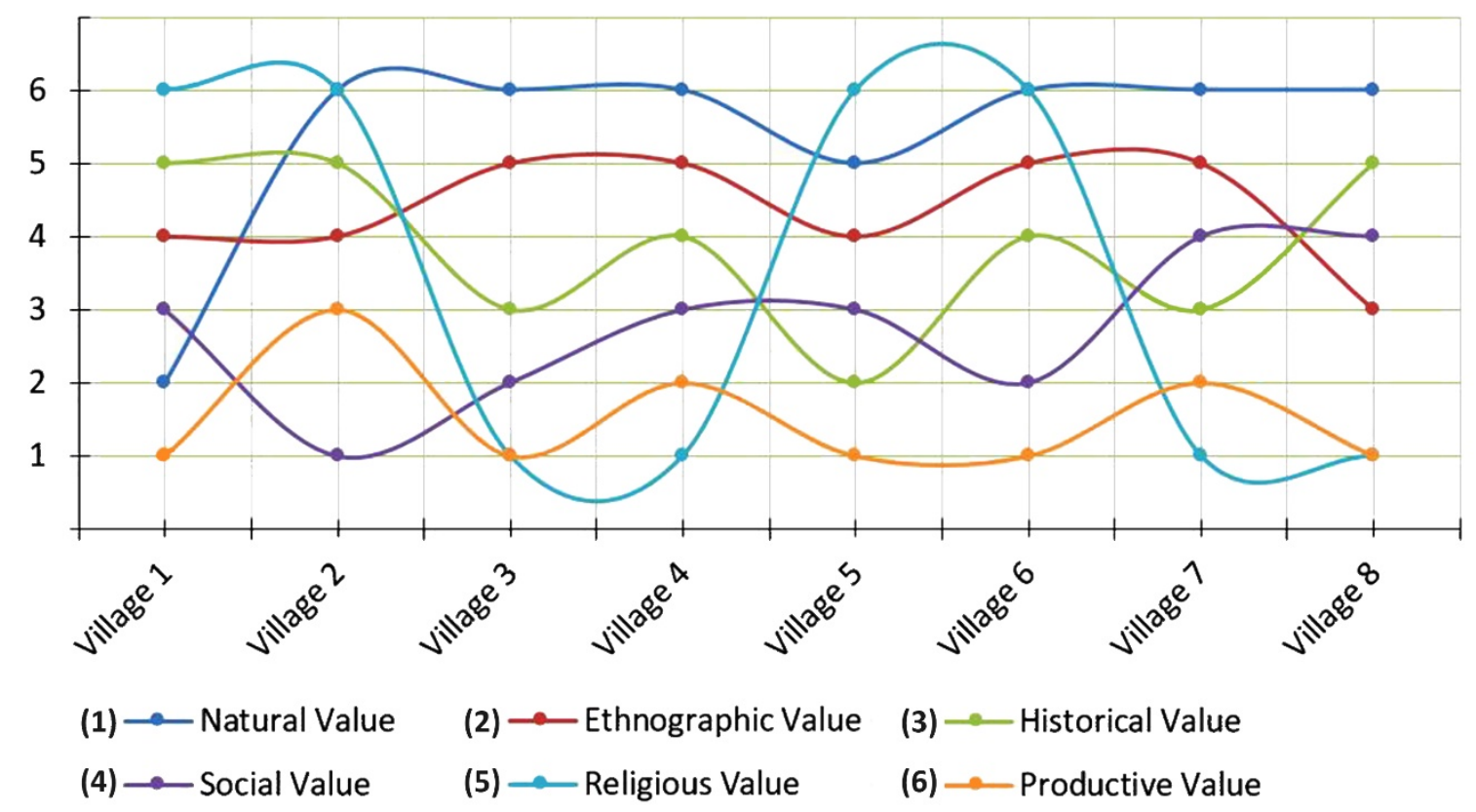

Figure 9 - Perception of the importance of the values of the landscape of Penyagolosa. Through Stephenson's theory (2010) it is possible to apply the hypothesis that one of the main characteristics of the landscape is that it is better understood and appreciated when the values it possesses are combined. In this case study, social perception was fragmented into categories (1- natural value, 2- ethnographic value, 3 historical value, 4- social value, 5- religious value and 6- productive value). Both the materiality of the landscape (e.g. Figure 1 or 8) and the perception of it (Figures 6, 7 and 9) or recent history show that values are complementary and connected. In other words, without a natural value there would be no ethnographic value, and without it there would be no productive value. The disconnection or different evolution of these values in the study area is evident in the physical environment (Figures 1 and 8), but the social perception of these values contradicts this assertion.

In all municipalities it was clearly seen that for the conservation of the landscape past cultural memory are of great value. It is assumed that there could be a disconnection from values due to the importance attached to historic, cultural or ethnographic values but evidence supported of the outputs of Figure 9, shows that these values can 
recognized among the population. Equally, the attachments or connection of society to the natural values are also present, although it is more surprising when socioeconomic values appear in last place, just because those values may generate resources such as rural tourism, or agriculture and livestock. In this context it is possible to see a single circumstance which validates the heritagization of the territory. Tradition is understood as a trigger for the future, making natural and cultural values necessary for boosting socioeconomic values.

\section{Identity}

Although the above results may be culturally conditioned, identity depends at least partly on collectives, not merely on cultures. Different cultures and the same identity can coexist within a collective (Grimson 2010). Collective identity is developed from a collective process of conscious 'seduction' or creation (Mira and Sanmartín 2007). Identity is a process developed from the bottom up and entails discovery, interpretation and so, understanding (Tilden 1957).

One hypothesis is that the rural changes currently occurring in this type of area create microidentities (Paniagua 2014) based on localisms. Participants ruled out this option in the participatory meetings, as long as, it was established that most people continue to feel attached to their origins or connected to the settlement from which their ancestors originally came, either the municipality or buildings scattered around it. It was demonstrated by the high percentage of response on the recognition of ethnographic, historical and religious values of the landscape (Figure 9). Most people felt they were represented by the heritage elements of their municipality, except in the case of mount Penyagolosa and its church. The mountain is seen as a symbolic identitarian element in all the municipalities. Life in the masías, with their architecture, tradition, nature, etc. 
lead to a shared landscape which facilitates a joint cultural image. It should be noted that as these data reflect a connection between the settlers and represent a feeling of belonging to a category, they are a key element in the culture of the region confirming the initial hypothesis. The limits of culture do not always coincide with those of identity and identities as outlined by administrations or created from bottom up are not always respected socially or culturally (first value to figure 9).

\section{Issues prior to heritagization}

Heritagizing the landscape means highlighting - and marketing - the most characteristic and symbolic values of a geographical area. It should be noted that heritage conceptualization is generated both from the locality and through institutions, whether governmental or NGO's (Clark and Drury 2000). Depending on the heritagization process which legitimates them, heritage landscapes are either those which provide an identity for their inhabitants and are assessed at a local level, or those recognized by institutions which assign them a value which is not merely local but based on regional, national or international values (Silva and Fernández 2017). A heritage location will not completely reflect its cultural resources and values if the inhabitants living within it are not involved in the heritagization process (Stephens and Tiwari 2015).

In connection with this it is worth referencing the rural gentrification processes closely linked to the identity of one class versus the power of another (Sorando and Ardura 2016). Alonso (2016) explains the awareness of this process within large urban areas, which appears so gradually in predominantly rural areas that it is not assimilated until it is fully consolidated. In addition to lacking a full acknowledgement of the values of the cultural landscape, gentrification can lead to an emphasis on the tourism economy and a 
loss of authenticity or traditional trades.

Heritage landscapes are currently seen as an economic resource, rather than the combination of all the factors which have determined the history, culture and identity of a given geographical region. According to this interpretation, heritage becomes an economic resource, a consumer good (Hernández 2009). The development of capitalist society has created basic consumer needs based on leisure and the tourist offer which have led to heritagization processes becoming part of a context of economic and social profitability (Urtizberea, Hernández and Andreu 2016).

Heritage processes should be seen as gradual, tentative, intermittent and inseparable from everyday life. The area under study reflects numerous conditioning factors and variables which require a process of reflection in order to understand the flow of tangible and intangible elements which make it up. For instance, there is a tendency to pass judgement from an individual standpoint on how everyday life will be affected by the changes stemming from heritagization. Heritagization processes are not usually altruistic, they all entail interests. They can even be valued from the uncertainty of future actions. It should be stressed that rather than results, what is truly important is the process which determines the future reality of the cultural landscape. Therefore, it can be concluded that there is no optimum heritagization process. Relationships and interactions between agents or actors must be as horizontal as possible, it must be an ethical task which ensures covering both the objective and subjective interpretations of the landscape. The long-term trajectory of the heritage phenomenon must be recognized, comprehended and accepted (Harvey 2001) to eventually be understood in depth. 


\section{How should heritagization be approached?}

The rural space analysed is undergoing complex transition processes on many different scales and rhythms, as stated by Pinto-Correia and Kristensen (2013). The study is understood as a landscape in continuous evolution, which inhabitants tend to value despite its continued degradation. Even if it is considered in poor or unaesthetic condition, it is still viewed as one more scene in daily life. A change of paradigm is thus highlighted, leaning towards the conceptual rather than the tangible. Evolution itself should serve collective memory, thus learning and teaching how to value, characterize and observe values. Although the current state may be considered bad or unsightly, it is one more everyday scene. This degradation can evolve into a paradigm shift. Evolution itself must serve residents and their collective memory to learn, teach to value, characterize and observe the current values of their daily landscapes. Thus, the analysis has shown that, regardless of the state of tangible resources in the landscape, intangible aspects continue to make sense of the landscape for residents. That is, recent theories consider that dynamic authenticity is based on current perception, action, experience and social practice, as well as the values of time and place (Pendlebury and Gibson 2009). These are objects that make or transform space, and are no longer part of it (Crang 2001). The authentically dynamic object is directly affected by contemporary decision-making processes and is the result of accumulated socio-cultural reconstructions of modest cultures. Its value therefore lies in how objects reflect circumstances rather than their own importance (García-Esparza 2018).

The region studied seeks future international recognition of the values found within this Mediterranean mountain cultural landscape. To do so, the material reality of the landscape must first be merged with its cultural image, focusing on four main aspects:

(1) Analysis of the territory, 
(2) Promotion and participation,

(3) Reflection on the guidelines to be followed, and

(4) Empowerment of the local population to determine the heritage future.

The structure proposed to start off the heritagization process covered all the initial concepts, all the opinions and contradictions generated by a landscape: Analysis of the fundamental values, criteria of authenticity and integrity, identity and belonging to the place and analysis of the elements that compose the area of study. With this in mind, before working on the guidelines to be followed, as indicated in (3) above, the question arose as to how heritagization ought to be approached. The analysis of the cultural landscape on the Penyagolosa region has shown how the combination of values which could be described as 'past' are still found among the population. It is therefore necessary to recognize the fabric of values, guaranteeing a balanced degree of integrity and authenticity both for the natural and cultural aspects of the landscape and the elements within it, in order to preserve resident's definition of their cultural heritage of the landscape.

There is on-going discussion in critical theory about the appropriate evolution of cultural landscapes (García-Esparza 2016). This is why the management of heritage spaces has to be reflected in improved protection, even when it remains unclear how the concepts of integrity and authenticity can become innovative and more dynamic in the landscape and its constructions. It is may be preferable for certain resources to conserve evidence of their historical origin rather than their full integrity, thus maintaining an active role in society, the economy and the landscape as a whole (Agnoletti 2014). The methodologies of Virtudes and Almeida (2016) in Portugal, Ferreti and Comino (2015), Ferreti, Bottero and Mondini (2014) in Italy or van der Vaart (2005) in the Netherlands among others have tried to guarantee these different degrees of cultural resource 
integrity.

Therefore, basic concepts are established for the rediscovery, understanding and reinterpretation of the cultural landscape. Using these as a starting point requires an understanding of the sociocultural perspective on landscape. The success of valorization or heritagization is greatly dependent on the social perspective attached to it, not in terms of literal reconstruction, fossilization or scenic reinterpretation (Owlig et al. 2016) and scenic landscape, but in terms of the importance of identity and culture in the collective memory of communities.

In order to secure the empowerment of the population there was a need to highlight values that were not obvious or were of little importance to them. Activities proposed included the Jornadas de Centros Históricos (2016, 2017 and 2018) where locals showed their vernacular homes and some ethnographic elements and organized tours around the town. Following consultation, the decision was made to work on uniting historical, ethnographic, cultural and natural values with social and economic values. Promoting the cultural landscape, even a deteriorated one, provides numerous valuable and appealing factors. This ensures that everyday elements of surroundings are valued and their character is recognized, creating the fabric of values mentioned in the introduction: democratising the landscape (Vik 2017) and making it transversal and understandable. These meetings with local residents highlighted how with the necessary respect between agents, the different perspectives created a joint understanding where everybody can learn from everybody else (García-Esparza 2015) conferring depth and validity to the concept of landscape and heritage. Attempts were made to unite the objective and subjective through participation to ensure a harmonious heritagization between users, neighbours and experts. 
However, it was necessary to work on feedback to avoid participation being used as a shield or simple validation method with no further implications (Sánchez-Carretero and Jiménez-Esquinas 2016). Fluid contact, criticism, self-criticism and understanding add to the concepts introduced initially. It should be stressed that the administration and legislation must be present in these processes for new heritage perspectives. A multidisciplinary team should lead these processes, remain sensitive to them and the social groups who support them and identify with the landscape. In order for this to be successful, the regional government and NGOs are essential within the framework of the comprehensive restructuring of landscape, while the fair distribution of loads and its benefits are key to success.

These landscapes which are now candidates for heritagization, have been cared for and shaped by residents and volunteers for centuries. Rather than an excuse for participation, this is a source of knowledge of the territory (Mydland and Grahn 2012). The combination of natural and cultural image to generate a new perspective of landscape includes the study - as seen earlier - of authenticity and symbolism, as reflected in the core values of residents and experts. This process for the recognition of past landscape is the means to create, conserve and manage the present cultural landscape and its varying layers of values and meaning.

Adopting a long-term strategy for the landscape of Penyagolosa is essential in order to successfully contextualize contemporary change (Emanuelson 2009). Heritage is also a process of communicating, transmitting and updating knowledge and ideas. It is about declaring and expressing identity, and re/creating the social and cultural values and meanings which back this up. Identities and memory are not simply found, produced or reflected in the heritage places and moments. Instead, they are recreated and negotiated continuously as people, communities and institutions reinterpret, remember, forget and 
reassess the meaning of the past in the social, cultural and political needs of the present (Smith 2011). Just as heritage and landscape require lengthy and lasting management processes, this management involves continuous study, prevention and action. These areas should either be kept alive and in a good state of conservation (Rossler 2012), or balance economic parameters and human, social and environmental wellbeing (Rivera et al. 2018).

\section{Conclusions}

Although the collaborations between locals and academics did cause some degree of tension (Pendlebury and Townshend 1999) due to differing interpretations of the same territory, it still appears to be the best possible form of analysis.

The basic premises stated at the start of this article sum up the historical conditioning factors linked to the characterization of landscape. It should be noted that although the heritage or landscape timelines and dynamics adapt to new trends, basic concepts are still useful for characterizing a given landscape and have been used in attempts to understand the disconnection between heritage agents. The evidence observed through citizen participation shows that an analysis of landscape should be linked to both the objective and subjective perspectives. Debating and learning more on an equal footing establishes transversal perspectives, creating heritage fabric and community. Ignoring subjectivity just because it is considered less realistic is to simplify the concept of landscape.

This study describes heritagization using general basic concepts. Highlighting and taking into account the main problems helped to tackle the concerns of the residents of the area under study. This has shown that empowering the local population in the heritagization process, making them participants in their surroundings, is to involve all 
collectives. Therefore, when heritagizing a setting it is important to work on the landscape from a human standpoint, focusing the process on the people who reside in the landscape and providing as many perspectives as possible through other actors and interest groups. Most of all, ensuring that this heritagization is gradual, even when its implementation is sorely needed, guarantees the integration of management within society, an understanding of the processes, and the adaptation of landscape to new uses or the recovery of traditional uses, consolidating collectively.

It should be remembered that the area shares with the rest of the Spanish state and some regions of Europe some severe problems that condition the environments. In this sense, using depopulation, environmental problems or the loss of heritage as a stimulus to establish starting points helped to unify analytical criteria and to focus participation as a debate in order to observe from within the attitude towards these problems and propose measures to try to reverse them.

The results of this study present landscape as an enormous source of heritage always connected to people. Returning to some of the current dynamics, redirecting them to new heritage paradigms which are more human and sustainable requires further consideration, study and understanding of the character of landscape at all levels and in all social strata.

\section{Acknowledgements}

This research has been developed with funding from the project "Intangible Cultural Heritage in Penyagolosa" from the Ministry of Culture, Education and Sports and the Institute of Cultural Heritage in Spain, CUL/1.A4/2018. And the project "Crafts and Artisans. Evaluation of small municipalities to develop a Patrimonial Territorial Action Plan" from the Regional Government of Valencia, Spain. GV/2017/100. 


\section{References}

Agnoletti, M. 2014. "Rural landscape, nature conservation and culture: Some notes on research trends and management approaches from a (southern) European perspective." Landscape and Urban Planning 126: 66-73.

Alonso, P. 2016. "Heritage and rural gentrification in Spain: the case of Santiago Millas.” International Journal of Heritage Studies 23 (2): 125-140.

Altaba, P. 2018. "The perception of heritage values and their analysis by using GIS tools in vernacular heritage landscapes." VITRUVIO - International Journal Of Architectural Technology And Sustainability 3 (1): 12-27.

Arias, D. 2011. "El co-relato de la imagen fotográfica: la arqueología visual como metodología en la exploración de la memoria etnohistórica." Quaderns-e de l'Institut Català d'Antropologia 16: 173-188.

Bignante, E. 2010. "The use of photo-elicitation in field research. Exploring Maasai representations and use of natural resources." EchoGéo 11. https://journals.openedition.org/echogeo/11622 (Consulted on August 10, 2018).

Berger, T. 2015. Autotopia, Suburban In-between Space in Israel. Tel-Aviv: Hakibbutz Hameuchad.

Butler, A. 2016. "Dynamics of integrating landscape values in landscape character assessment: the hidden dominance of the objective outsider." Landscape Research 41 (2): 239-252.

Clark, K., and Drury, P. 2000. "From monuments to people: the functions of cultural heritage in a changing Europe." In Forward Planning: The functions of Cultural Heritage in a Changing Europe, edited by Therond, B., and Council of Europe 113-117. Strasbourg: Council of Europe.

Council of Europe. 2000. European Landscape Convention. Florence.

Crang, M. 2001. "Rhythms of the city: temporalised space and motion." In TimeSpace: Geographies of Temporality, edited by J. May. and N. Thrift, 187-207. London, New York: Routledge.

Dalglish, C., and A. Leslie. 2016. "A question of what matters: landscape characterization as a process of situated, problem-orientated." Landscape Research 41 (2): 212-226.

De la Torre, M. 2013. "Values and Heritage Conservation." Heritage \& Society 60 (2): 155-166. 
Emanuelson, U. 2009. The rural landscapes of Europe - How man has shaped European nature. Stockholm: Swedish Research Council Formas.

English Heritage. 2008. Conservation Principles: Policies and Guidance for the Sustainable Management of the Historic Environment. London: Author.

Fairclough, G. 2012. "A prospect of time. Interactions between landscape architecture and archaeology." In Exploring the boundaries of landscape architecture, edited by Simon Bell, Ingrid Sarlöv Herlin, Richard Stiles, 83-114. London, New York: Routledge.

Ferreti, V., and E. Comino. 2015. "An integrated framework to assess complex cultural and natural heritage systems with Multi-Attribute Value Theory." Journal of Cultural Heritage 16 (5): 688-697.

Ferreti, V., M. Bottero, and G. Mondini. 2014. "Decision making and cultural heritage: An application of the Multi-Attribute Value Theory for the reuse of historical buildings." Journal of Cultural Heritage 15 (6): 644-655.

Folch, R. and J. Bru. 2017. Ambiente, territorio y paisaje. Valores y valoraciones. Barcelona: Editorial Barcino.

Fredheim, L., and M. Khalaf. 2016. "The significance of values: heritage value typologies re-examined." International Journal of Heritage Studies 22 (6): 466481.

García-Esparza, J. A. 2015. "Epistemological paradigms in the perception and assessment of vernacular architecture.” International Journal of Heritage Studies 21 (9): 869-888.

García-Esparza, J. A. 2016. "Re-thinking the validity of the past. Deconstructing what authenticity and integrity mean to the fruition of cultural heritage." VITRUVIO International Journal of Architectural Technology and Sustainability 1 (1): 2134.

García-Esparza, J. A. 2018. "Are World Heritage concepts of integrity and authenticity lacking in dynamism? A critical approach to Mediterranean autotopic landscapes." Landscape Research 43 (6): 817-830.

Gasco, J., and X. Gutherz. 1983. Premiers paysans de la France méditerranéenne. Montpellier, France: Direction du Patrimoine du Ministère de la Culture.

Grimson, A. 2010. "Culture and Identity: two different notions." Social Identities 16 (1): 63-79. 
Gullino, P., and F. Larcher. 2013. "Integrity in UNESCO World Heritage Sites. A comparative study for rural landscapes." Journal of Cultural Heritage 14 (5): 389-395.

Hammitt, W., E. Backlund, and R. Bixler. 2006. "Place bonding for recreation places: conceptual and empirical development." Leisure Studies 25 (1): 17-41.

Hammitt, W., G. Kyle, and C. Oh. 2009. "Comparison of place bonding models in recreation resource management." Journal of Leisure Research 41 (1): 57-72.

Harrison, R. 2015. "Beyond "Natural" and "Cultural" Heritage: Toward an Ontological Politics of Heritage in the Age of Anthropocene.” Heritage \& Society 8 (1): 24 42.

Harper, D. 2002. “Talking about pictures: a case for photo elicitation.” Visual Studies 17 (1) $13-26$.

Harvey, D. 2001. "Heritage Pasts and Heritage Presents: temporality, meaning and the scope of heritage studies." International Journal of Heritage Studies 7 (4): 319338.

Hernández, M. 2009. "El paisaje como seña de identidad territorial: valoración social y factor de desarrollo, ¿utopía o realidad?” Boletín de la A.G.E 49: 169-183.

Holmes, J. 2012. “Cape York Peninsula, Australia: A frontier region undergoing a multifunctional transition with indigenous engagement." Journal of Rural Studies 28 (3): 252-265.

ICOMOS. 1994. The Nara Document on Authenticity. París: Author.

ICOMOS. 2000. The Burra Charter: The Australia ICOMOS charter for places of cultural significance 1999: with associated guidelines and code on the ethics of co-existence. Australia: Author.

Jackson, J.B. 1990. "The future of the vernacular landscape.” In Vision, culture and landscape edited by Groth, P., 27-39. Berkeley: University of California.

Kyle, G., A. Graefe, and R. Manning. 2005. "Testing the dimensionality of place attachment in recreation settings." Environment and behavior 37 (2): 153-177.

Kyle, G., A. Mowen, and M. Tarrant. 2004. "Linking place preferences with place meaning: an examination of the relationship between place motivation and place." Journal of environmental psychology 24 (4) 439-454.

Mira, J. F. 2007. Identitat i territori: els cercles de la cosnciencia. València: Servei de Publicacions de la Universitat de València. 
Mira, J. F., and R. Sanmartín. 2007. "L'Antropologia del detall: una conversa entre Joan Francesc Mira i Ricardo Sanmartíb sobre identitat, multiculturalisme i societat glocal." Revista valenciana d'etnologia 2: 13-32.

Mydland, L., and W. Grahn. 2012. "Identifying heritage values in local communities." International Journal of Heritage Studies, 18 (6): 564-587.

Olwig, K., C. Dalglish, G. Fairclough, and P. Herring. 2016. "Introduction to a special issue: the future of landscape characterisation, and the future character of landscape - between space, time, history, place and nature." Landscape Research 41 (2): 169-174.

Paniagua, A. 2014. "Rurality, identity and morality in remote rural areas in northern Spain.” Journal of Rural Studies 35: 49-58.

Parkinson, A., M. Scott, and D. Redmond. 2016. "Competing discourses of built heritage: lay values in Irish conservation planning." International Journal of Heritage Studies 22 (3): 261-273.

Pendlebury, J. 2013. "Conservation values, the authorised heritage discourse and the conservation-planning assemblage.” International Journal of Heritage Studies 19 (7): 709-727.

Pendlebury, J., and L. Gibson. 2009. "Valuing historic environments.” In Valuing historic environments edited by Pendlebury, J., and L. Gibson, 1-18. Farnham: Ashgate.

Pendlebury, J., T. Townshend. 1999. "The Conservation of Historic Areas and Public Participation." Journal of Architectural Conservation 5 (2): 72-87.

Pinto-Correia, T.,and L. Kristensen. 2013. "Linking research to practice: The landscape as the basis for integrating social and ecological perspectives of the rural." Landscape and Urban Planning 120: 248-256.

Plottu, E., and B. Plottu. 2012. “Total landscape values: a multidimensional approach.” Journal of Environmental Planning and Management 55 (6): 797-811.

Pocock, C., D. Collett, and L. Baulch. 2015. “Assessing stories before sites: identifying the tangible from the intangible." International Journal of Heritage Studies 21 (10): 962-982.

Riesco, P., J. Gómez, J., and D. Álvarez. 2008. "Región, comarca, lugar: escalas de referencia en la metodología del paisaje.” Cuadernos Geográficos 43: 227-255.

Rivera, M., K. Knickel, I. de los Rios, A. Ashkenazy, D. Qvist Pears, T. Chebach, and S. Sumane. 2018. "Rethinking the connections between agricultural change and 
rural prosperity: A discussion of insights derived from case studies in seven countries." Journal of Rural Studies, 59: 242-251.

Rossler, M. 2012. "Partners in Site Management a Shift in Focus: Heritage and Community Involvement". In Community Development through World Heritage edited by Witcomb, A., M. Albert, M. Viñals, and M. Richon, 27-32. París: UNESCO.

Sánchez-Carretero, C., and G. Jiménez-Esquinas, G. 2016. "Relaciones entre actores patrimoniales: gobernanza patrimonial, modelos neoliberales y procesos participativos." Revista Ph. 90: 190-197, http://www.iaph.es/revistaph/index.php/revistaph/article/view/3827 (Consulted on August 10, 2018).

Silva, R., and V. Fernández. 2017. "El nuevo paradigma del patrimonio y su consideración con los paisajes: Conceptos, métodos y prospectivas." Documents d'Anàlisi Geogràfica 63 (1): 129-151.

Smith, L. 2006. The uses of heritage. London: Routledge.

Smith, L. 2011. "El “espejo patrimonial”. ¿ilusión narcisista o reflexion es múltiples?" Antípoda. Revista de Antropología y Arqueología 12: 39-63.

Smith, L. 2013. “Editorial.” Internacional Journal of Heritage Studies 19 (4): 325-326. Sorando, D., and A. Ardura. 2016. First we take Manhattan: la destrucción creativa de las ciudades. Madrid: Catarata.

Speed, J., G. Austrheim, H. Birks, S. Johnson, M. Kvamme, L. Nagy, P. Sjögren, et al. 2012. "Natural and cultural heritage in mountain landscapes: towards an integrated valuation." International Journal of Biodiversity Science, Ecosystem Services \& Management 8 (4): 313-320.

Spennermann, D. H. 2006. "Gauging Community Values in Historic Preservation.” CRM: WASHINGTON 3(2): 6-20.

Stephens, J., and R. Tiwari. 2015. "Symbolic estates: community identity and empowerment through heritage.” International Journal of Heritage Studies 21 (1): 99-114.

Stephenson, J. 2008. "The Cultural Values Model: An Integrated Approach to Values in Landscapes.". Landscape and Urban Planning 84 (2): 127-139.

Stephenson, J. 2010. “The dimensional landscape model: Exploring differences in expressing and locating landscape qualities.” Landscape Research 35 (3): 299318. 
Stobbelaar, D., and B. Pedroli. 2011. "Perspectives on Landscape Identity: A Conceptual Challenge." Landscape Research 36 (3): 321-339.

Swanwick, C. 2002. Landscape Character Assessment: Guidance for England and Scotland. The Countryside Agency and Scottish Natural Heritage.

Tilden, F. 1957. Interpreting our Heritage: Principles and practices for visitor services in parks, museums, and historic places. University of North Carolina Press.

Tudor, C. 2014. An approach to landscape character assessment. Natural England.

Urtizberea, I., E. Hernández, and A. Andreu. 2016. "Patrimonio local en un mundo global: procesos de patrimonialización cultural en contextos locales de Andalucía y el País Vasco.” Memória em Rede 8 (14): 41-57.

van der Vaart, J. 2005. “Towards a new rural landscape: consequences of nonagricultural re-use of redundant farm buildings in Friesland." Landscape and Urban Planning 70 (1-2): 143-152.

Vik, M. 2017. "Self-mobilisation and lived landscape democracy: local initiatives as democratic landscape practices." Landscape Research 42 (4): 400-411.

Virtudes, A., and F. Almeida. 2016. "ICT Method for Evaluation of Heritage Buildings Conservation." Procedia Engineering 161: 1910-1914.

Watson, S., and E, Waterton. 2010. "Editorial. Heritage and community engagement." International Journal of Heritage Studies 16 (1-2): 1-3. 